\title{
POTENTIAL AMELIORATIVE ROLE OF N-ACETYLCYSTEINE AGAINST TESTICULAR DYSFUNCTION INDUCED BY TITANIUM DIOXIDE IN MALE ALBINO RATS
}

\author{
${ }^{1,2}$ Ahmed Farag El-Kirdasy, ${ }^{3}$ Mohamed Abdo Nassan, ${ }^{4,5}$ Ahmed Abdel Aziz Baiomy, \\ ${ }^{6,7}$ Tamer Ahmed Ismail, ${ }^{6,8}$ Mohamed Mohamed Soliman and ${ }^{6,9}$ Hossam Fouad Attia \\ ${ }^{1}$ Department of Biochemistry, College of Veterinary Medicine, Sadat City University, Egypt \\ ${ }^{2}$ Department of Biomedical Sciences, College of Pharmacy, Shaqraa University, Saudi Arabia \\ ${ }^{3}$ Department of Pathology, Faculty of Veterinary Medicine, Zagazig University, Egypt \\ ${ }^{4}$ Department of Biotechnology, Faculty of Applied Medical Sciences, Turabah, Taif University, Saudi Arabia \\ ${ }^{5}$ Department of Zoology, Faculty of Science, Cairo University, Egypt \\ ${ }^{6}$ Department of Medical Laboratory, Faculty of Applied Medical Sciences, Turabah, Taif University, Saudi Arabia \\ ${ }^{7}$ Department of Physiology, Faculty of Veterinary Medicine, Zagazig University, Egypt \\ ${ }^{8}$ Department of Biochemistry, \\ ${ }^{9}$ Department of Histology and Cytology, \\ Faculty of Veterinary Medicine, Benha University, Egypt
}

Received 2013-12-10; Revised 2013-12-22; Accepted 2013-12-31

\begin{abstract}
In this study, we examined the ameliorative action of N-Acetylcysteine (NAC) against Titanium Dioxide (TiO2) induced testicular degeneration in albino rats. Adult male albino rats were given saline as a control group, TiO2 (1200 mg kg $\mathrm{mb}^{-1} \mathrm{BW}$, NAC (100 mg kg$\left.{ }^{-1} \mathrm{BW}\right)$ and co-treatment of NAC and TiO2 as a protective group for 3 months. Testicular tissues were extracted for changes in testicular gene expression and histopathology. Administration of TiO2 significantly up-regulated mRNA expression of IL-6 and TNF- $\alpha$ and normalized by NAC administration. TiO2 administration down regulated Glutathione-S-Transferase (GST) while increased B-cell Lymphoma2 (BcL2) expressions. Co-administration of rats by NAC together with TiO2 normalized changes in GST and BcL2 expression. Expression of steroidogenesis related genes [Androgen Binding Protein (ABR), 17 $\beta$-Hydroxysteroid Dehydrogenase (17 $\beta$-HSD), cytochrome P450 17A (CYP17 $\alpha$ ) and aromatase] showed down regulation in $\mathrm{TiO} 2$ administered groups and normalized when NAC given together with $\mathrm{TiO} 2$. Moreover, $\mathrm{TiO} 2$ induced toxicity in testes that accompanied by degeneration in seminiferous tubules with congestion, oedema and cell disruption that are partially normalized by co-administration of NAC with TiO2. In conclusion, the present findings confirmed the benficial effect of NAC to prevent apoptosis in spermatogenic and sertoli cells and testicular dysfunction induced by $\mathrm{TiO} 2$ in male albino rats.
\end{abstract}

Keywords:Titanium Dioxide, N-acetylcysteine, Steroidogenesis Related Enzymes, Gene Expression, Testicular Dysfunction and Apoptosis

\section{INTRODUCTION}

Titanium Dioxide (TiO2) is widely used as an additive, in paints, in sunscreens and in cosmetics $s$ as well as in the environmental decontaminant for air, water and soil by the destruction of pesticides (Fisher and Egerton, 2001; Kaida et al., 2004; Choi et al., 2006; Medina et al., 2007). The rate of cellular damage and oxidative stress of nanoparticles are attributed to the particle size and chemical composition (Hoet et al., 2004). The smaller

Corresponding Author: Mohamed Mohamed Soliman, Department of Biochemistry, Faculty of Veterinary Medicine,

University, Egypt Tel: 00966501531640; 002012-3722404 
the particles of $\mathrm{TiO} 2$, the more reactivity, effectivity and toxicity (Oberdorster, 2006). Oxidative stress induced serious toxicity in body tissues as in lung, kidney, testes, brain and spleen (Li et al., 2010; Sang et al., 2012). Higher doses of TiO2 nanoparticles (324-2592 $\mathrm{mg} \mathrm{kg}^{-1}$ bw) are accumulated in various organs as spleen, liver, kidney, lung and testes (Chen et al., 2009). Upon exposure to $\mathrm{TiO} 2$, pathological lesions occur in the liver, spleen, kidneys, testes and brain (Shi et al., 2013; Jia et al., 2013). Consequently disruption in organ function occur and alteration in inflammatory and defensive mechanisms of body. Testes are rich in polyunsaturated fatty acids which are the source of ROS. Accumulated data showed that ROS-mediated oxidative stress, alters cellular testes damage (Turner and Lysiak, 2008). ROS regulated antioxidant defense systems through regulation of reduced glutathione activity.

As known, N-Acetylcysteine (NAC) is an antioxidant used extensively as an additive in conditional nutrient (Moschou et al., 2008). NAC acts as a cysteine supplier, maintains or even increases the intracellular levels of glutathione (Stanislawski et al., 2000; 2003; Van de Poll et al., 2006; Sadowska et al., 2007; Atkuri et al., 2007). NAC free thiol group can interacts with electrophilic groups of ROS (Sen and Packer, 2000). It has a protective effect on a wide range of cell types (Cay et al., 2006). Zafarullah et al. (2003) reported that cell growth and survival rate increased as a counteract mechanism to ROS-induced injuries resulated in growth arrest and apoptosis. Thus, NAC can restore the imbalance between pro-oxidant and antioxidant systems during oxidative stress. NAC is safe and well tolerated when administered orally while intravenous administrationof NAC induced some helath problems (Dodd et al., 2008). Rarely, higher doses of NAC causes skin affection as rashes, fever, headache. It may cause drowsiness, low blood pressure and liver problems (Dodd et al., 2008).

Cytokines are proteins that are secreted and expressed by most of cell types (Feghali and Wright, 1997). They are pharmacologically active with either beneficial or pathologic actions on the target cells. They may pro-inflammatory, inflammatory or antiinflammatory proteins secreted to maintain body defensive mechanism. Imbalanced expression of cytokines are involved in progression of many diseases (Arend and Gabay, 2004). Their expression reflect the immune and health state of the body. In this study, we investigated the effects of $\mathrm{NAC}$ on $\mathrm{TiO} 2$ induced alterations in gene expression of steroidogenesis, reduced Glutathione (GST), testicular inflammatory and apoptotic activity (IL-6 and TNF- $\alpha$ and BcL2 respectively) and testes histopathology and possible protection by NAC in male albino rats. The enzymes of steroidogenesis examined are Androgen Binding Protein (ABR), 17 $\beta$-hydroxysteroid dehydrogenase (17 $\beta$-HSD), Cytochrome P450 17A (CYP17 $\alpha)$ and aromatase.

\section{MATERIALS AND METHODS}

\subsection{Materials and Animals}

Ethidium bromide, agarose and $\mathrm{TiO} 2$ anatase form, particle size $(25-70 \mathrm{~nm})$ were purchased from Sigma Aldrich Co., MO, USA. The male albino rats were purchased from Egyptian Co for Experimental Animals Import, Helwan, Cairo, Egypt. Gum acacia and NAC were obtained from El-Nasr Co., Cairo, Egypt. Cytokines primers were from MACROGEN, Seoul, Korea. Twenty four male albino rats weighting 150-200 $\mathrm{g}$ were obtained from the Animal House in Faculty of Veterinary Medicine, Benha Universitiy. Rats gained free access to food and water with $12 \mathrm{~h} / 12 \mathrm{~h}$ dark light cycle. All animals were left one week for adaptation. They were housed in separate well-ventilated cages, under standard conditions.

\subsection{Experimental Design}

Twenty four rats were divided into 4 groups (6 rats per group). Group I (control group), were kept under standard conditions, fed on balanced diet for 3 months. Group II (NAC treated group) received $100 \mathrm{mg} \mathrm{kg}^{-1}$ body weight NAC once daily by gastric gavage for 3 months. Group III (TiO2 treated group) received 1200 $\mathrm{mg} \mathrm{kg}^{-1}$ body weight $\mathrm{TiO} 2$ by gavage (1/10 LD 50) in $1 \mathrm{~mL}$ of $5 \%$ gum acacia solution as a solvent once daily for 3 months. The dose of $\mathrm{TiO} 2$ was used based on studies of (Wang et al., 2007). Group IV (NAC+TiO2) received $100 \mathrm{mg} \mathrm{kg}^{-1}$ body weight NAC one hour before $\mathrm{TiO} 2$ by gavage once daily for 3 months. At the end of the experiments, the rats were sacrificed. Blood and testes were taken for histopathology and gene expression.

\subsection{RNA Extraction and cDNA Synthesis}

For preparation of total RNA, testes (approximately $100 \mathrm{mg}$ per sample) were collected from rats, flash frozen in liquid nitrogen and subsequently stored at $-70^{\circ} \mathrm{C}$ in $1 \mathrm{~mL}$ Qiazol (QIAGEN 
Inc., Valencia, CA). Frozen samples were homogenized using a Polytron 300 D homogenizer (Brinkman Instruments, Westbury, NY). Chloroform $(0.3 \mathrm{~mL})$ were added to the homogenate. After shaking for 30 seconds, the mixture was centrifugated at $4^{\circ} \mathrm{C}$ and $12,500 \mathrm{rpm}$ for $20 \mathrm{~min}$. The aquatic supernatant layer was transferred and an equal volume of isopropanol was added in new sets of tubes, then shacked for $15 \mathrm{sec}$ and centrifuged at $4^{\circ} \mathrm{C}$ and 12,500 $\mathrm{rpm}$ for $15 \mathrm{~min}$. The pellets of RNA were washed with $70 \%$ ethanol and dissolved in Diethylpyrocarbonate (DEPC) water. Electrophoresis was used to check RNA integrity. RNA concentration and purity were determined spectrophotometrically at $260 \mathrm{~nm}$. The ratio of OD (260/280) for all samples was ranged from 1.7 to 1.9 .

For cDNA synthesis, $2 \mu \mathrm{g}$ of total RNA and $0.5 \mathrm{ng}$ oligo dT primer in a total volume of $11 \mu \mathrm{L}$ sterilized DEPC water were incubated in the PeX 0.5 thermal Cycler (Thermo Electronic Corporation, Milford, Ma) at $65^{\circ} \mathrm{C}$ for $10 \mathrm{~min}$ for denaturation. Then, $4 \mu \mathrm{L}$ of $5 \mathrm{X}$ RTbuffer, $2 \mu \mathrm{L}$ of $10 \mathrm{mM}$ dNTPs and $100 \mathrm{U}$ Moloney Murine Leukemia Virus (M-MuLV) Reverse Transcriptase (SibEnzyme Ltd. Ak, Novosibirsk, Russia) were added and the total volume was completed up to 20 $\mu \mathrm{L}$ by DEPC water. Finally, the mixture was incubated in the thermal cycler at $37^{\circ} \mathrm{C}$ for $1 \mathrm{~h}$ and at $90^{\circ} \mathrm{C}$ for 10 min to ensure enzyme inactivation.

\subsection{Semi-Quantitative PCR Analysis}

Specific primers for our examined genes as shown in table 1 were designed using Oligo-4 computer program and synthesized by Macrogen (Macrogen Company, GAsa-dong, Geumcheon-gu. Korea). PCR reaction ( $25 \mu \mathrm{L}$ total volume) was consisted of $1 \mu \mathrm{L}$ cDNA, $1 \mu \mathrm{L}$ of 10 picomolar (pM) of each primer (forward and reverse) and 12.5 $\mu \mathrm{L}$ PCR master mix
(Promega Corporation, Madison, WI) the volume was brought up to 25 using sterilized, deionized water. PCR was carried out using a PeX 0.5 thermal Cycler at $94^{\circ} \mathrm{C}$ for for $5 \mathrm{~min}$ one cycle, followed by variable cycles (according to degree of gene expression) each of which consisted of denaturation at $94^{\circ} \mathrm{C}$ for one minute, annealing temperature as seen in table 1 and extension at $72{ }^{\circ} \mathrm{C}$ for $1 \mathrm{~min}$, with additional final extension at $72^{\circ} \mathrm{C}$ for $7 \mathrm{~min}$. As a reference, expression of glyceraldehyde-3-phosphate dDehydrogenase (G3PDH) mRNA was used. PCR products were visualized by electrophorrsis in $1.5 \%$ agarose gel (Bio Basic INC. Konrad Cres, Markham Ontario), stained with ethidium bromide in TBE (TrisBorate-EDTA) buffer. PCR products were photographed using gel documentation system. The intensities of the bands were quantified using ImageJ software (http://imagej.en.softonic.com/).

\subsection{Histopathological Examination}

The testes of rats at the end of experimetal procedures were collected and fixed in Bouin's solution and dehydrated in ascending grades of alcohols, cleared in xylene and embedded in paraffin. The samples were casted, then sliced into $5 \mu \mathrm{m}$ thickness and placed onto glass slides. The slides were stained by general and specific stains (Wilson and Gamble, 2008). PAS and Masson's Trichrome reactions were carried out based on protocols of Kiernan (1999) and Carson (1990) respectively.

\subsection{Statistical Analysis}

Results are expressed as means \pm S.E of 5 different rats per each group. Statistical analysis was done using ANOVA and Fischer's post hoc test, with $\mathrm{p}<0.05$ being considered as statistically significant.

Table 1. PCR conditions for rat cytokines and spematogenesis genes

\begin{tabular}{|c|c|c|c|}
\hline Gene & Forward primer & Reverse primer & PCR cycles and Ann. Temp. \\
\hline$\overline{\mathrm{IL}-6}$ (450bp) & 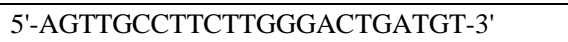 & 5'-TGCTCTGAATGACTCTGGCTTTG-3' & 30 cycles, $57^{\circ} \mathrm{C} 1 \mathrm{~min}$ \\
\hline TNF- $\alpha(256$ bp $)$ & 5'- CCACCACGCTCTTCTGTCTAC-3' & 5'-ACCACCAGTTGGTTGTCTTTG-3' & 30 cycles, $58^{\circ} \mathrm{C} 1 \mathrm{~min}$ \\
\hline $\mathrm{BcL} 2(350 \mathrm{bp})$ & 5' TCC ATT ATA AGC TGT CAC AGA GG -3' & 5'-- GAA GAG TTC CTC CAC CAC C -3' & 30 cycles, $55^{\circ} \mathrm{C} 1 \mathrm{~min}$ \\
\hline GST (575 bp) & 5'- GCTGGAGTGGAGTTTGAAGAA-3' & 5'- GTCCTGACCACGTCAACATAG -3' & 33 cycles, $55^{\circ} \mathrm{C} 1 \mathrm{~min}$ \\
\hline ABP (195 bp) & 5'- CCATTCCTCCTTTGAGTTTCGA-3' & 5'- CAGCTCCACCCGGGTGC-3' & 35 cycles, $65^{\circ} \mathrm{C} 45 \mathrm{sec}$ \\
\hline Aromatase (142 bp) & 5'- GCCTGTCGTGGACTTGGT -3' & 5'-GGTAAATTCATTGGGGTTGG -3' & 33 cycles, $57^{\circ} \mathrm{C} 1 \mathrm{~min}$ \\
\hline CYP17 $\alpha(138) b p$ & 5'- GCTAACATTGACTCCAGCATTGG-3' & 5'-GAAGCGCTCAGGCATAAACC-3' & 33 cycles, $60^{\circ} \mathrm{C} 1 \mathrm{~min}$ \\
\hline $17 \beta$-HSD (114 bp) & 5'- CTCTGGGCACTGCATCAC-3' & 5'- CAAGTAACTCTGCGTGGGT-3' & 33 cycles, $53^{\circ} \mathrm{C} 1 \mathrm{~min}$ \\
\hline GAPDH (309 bp) & 5'-AGATCCACAACGGATACATT-3 & 5-TCCCTCAAGATTGTCAGCAA-3' & 25 cycles, $52^{\circ} \mathrm{C} 1 \mathrm{~min}$ \\
\hline
\end{tabular}




\section{RESULTS}

\subsection{IL-6 and TNF- $\alpha$ Expression in Testes after TiO2 and NAC Administration in Male Albino Rats}

Administration of $\mathrm{TiO} 2$ to rats for 3 months upregulated IL- 6 and TNF- $\alpha$ expression in testes and their expression was normalized in rats administered NAC together with $\mathrm{TiO} 2$ (Fig. $1 \mathrm{a}$ and b). NAC administeration to rats alone has no effect on IL-6 and TNF- $\alpha$ expression.
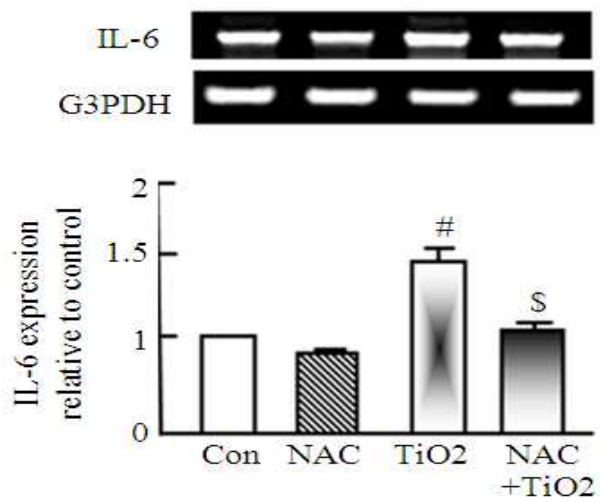

(a)
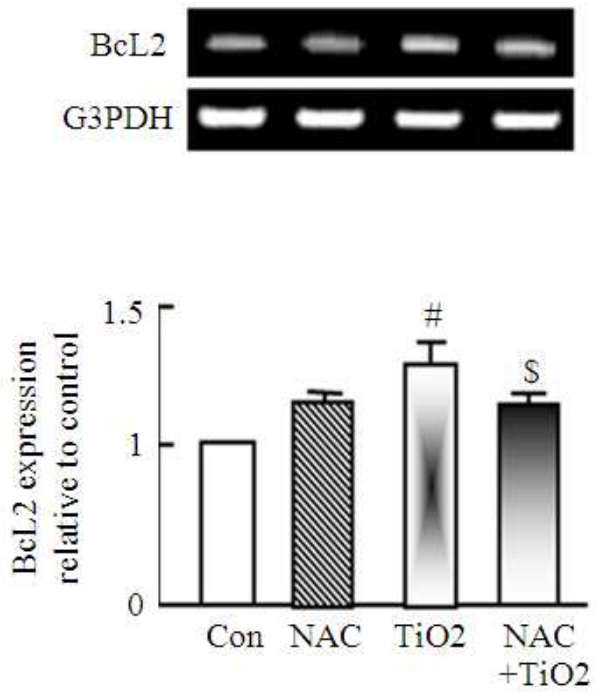

(c)

\subsection{BcL2 and GST Expression in Testes after TiO2 and NAC Administration in Male Albino Rats}

To test the antiapoptotic and antioxidant effect of NAC, we tested the expression of BcL2 and GST after administration of $\mathrm{TiO} 2$ or NAC either alone or together. Figure 1c and d, show that $\mathrm{TiO} 2$ increased BcL2 expression and decreased expression of GST and administration of NAC together with $\mathrm{TiO} 2$ normalized such increase in BcL2 expression and the decrease in GST expression.
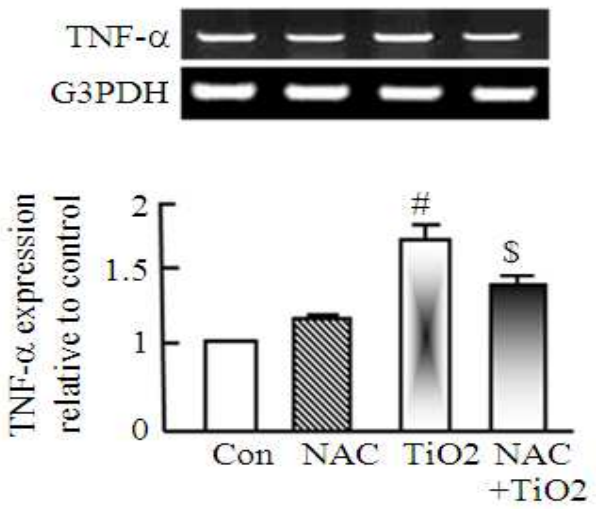

(b)
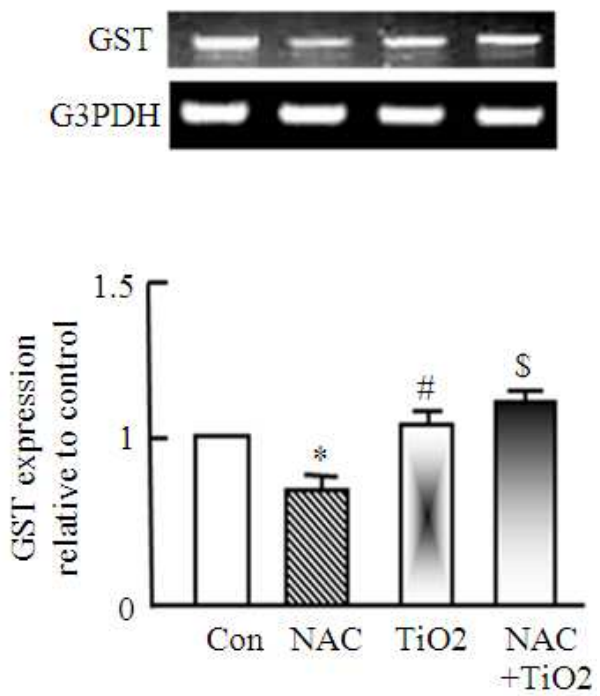

(d)

Fig. 1. RT-PCR expression of IL-6, TNF- $\alpha, \mathrm{BcL} 2$ and GST expression after administration of either NAC or TiO2 alone or together in Albino rats. NAC and TiO2 were administered for 3 months as described in materials and methods. RNA was extracted and reverse transcribed $(3 \mu \mathrm{g})$ and RT-PCR analysis was carried out for of IL-6, TNF- $\alpha$, BcL2 and GST genes. Densitometric analysis was carried for 3 different rats. ${ }^{*} \mathrm{p}<0.05 \mathrm{Vs}$ control while \# $\mathrm{p}<0.05 \mathrm{Vs}$ NAC group and $\$ \mathrm{p}<0.05 \mathrm{Vs} \mathrm{TiO} 2$ 


\subsection{Expression of Steroidogenesis Regulating Enzymes in Testis of Albino Rats after TiO2 and NAC Administration}

To test the effect of the pollutant on genes of testosterone biosynthesis, rats were treated with and/or without $\mathrm{TiO} 2$ in presence or absence of NAC. The expression of ABP, 17 $\beta$-HSD, CYP17 $\alpha$ and aromatase were examined using RT-PCR analysis. As seen in Fig. 2a, $\mathrm{TiO} 2$ induced significant decrease in ABP expression but in presence of NAC the suppression was normalized and increased. The down
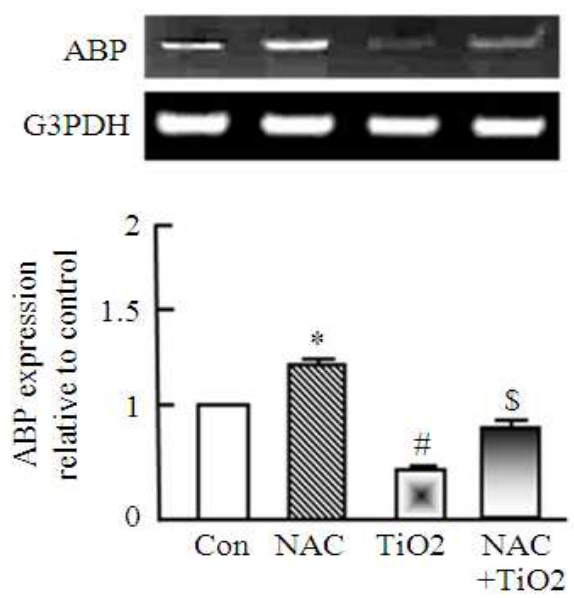

(a)
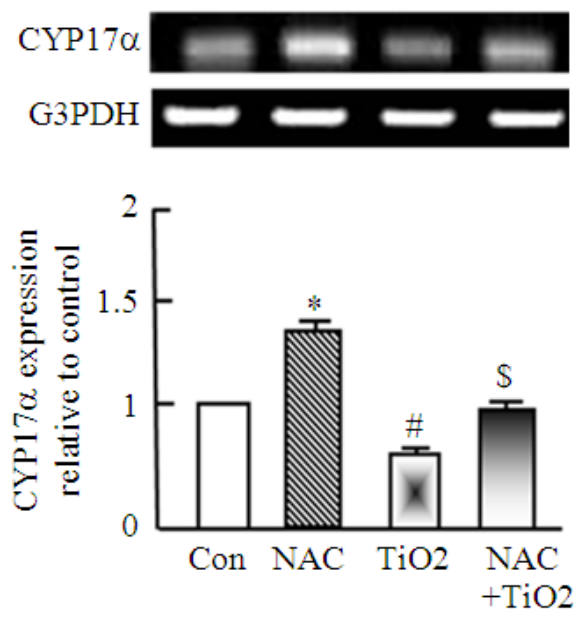

(c) regulation in $\mathrm{ABP}$ expression was around $55 \%$ of normal expression. Also, NAC inhibited $\mathrm{TiO} 2$ induced $70 \%$ down regulation in aromatase expression that was normalized in presence of NAC (Fig. 2b). Next, we examined the expression of CYP17 $\alpha$ that plays a role in the biosynthesis of steroid hormones. TiO2 induced $43 \%$ down regulation in CYP17 $\alpha$ expression in testis. Presence of NAC with $\mathrm{TiO} 2$ significantly normalized the expression of CYP17 $\alpha$ (Fig. 2c). Next, we tested the expression of $17 \beta-H S D$, the enzyme responsible for synthesis of testosterone from androstenedione.


(b)
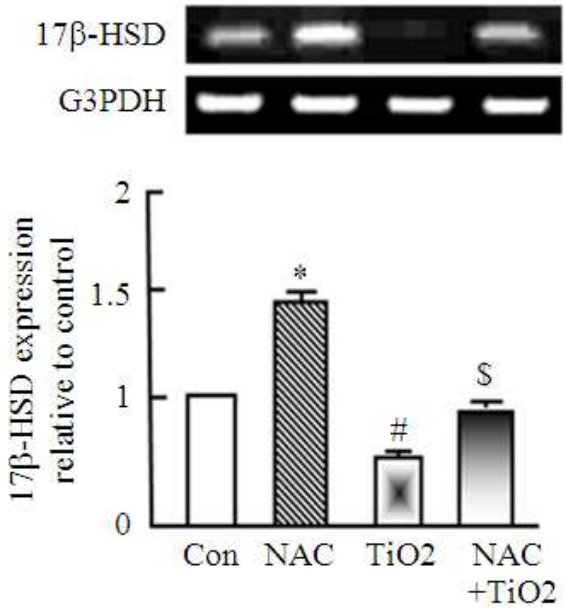

(d)

Fig. 2. RT-PCR expression of steroidogensis related gene expression after administration of either NAC or TiO2 alone or together in Albino rats. NAC and TiO2 were administered for 3 months as described in materials and methods. RNA was extracted and reverse transcribed $(3 \mu \mathrm{g})$ and RT-PCR expression was done for the changes in ABP, aromatase, CYP17 $\alpha$ and $17 \beta-H S D$ genes. Densitometric analysis was carried for 3 different rats. ${ }^{*} \mathrm{p}<0.05 \mathrm{Vs}$ control while \# $\mathrm{p}<0.05 \mathrm{Vs}$ NAC group and $\$ \mathrm{p}<0.05 \mathrm{Vs}$ TiO 


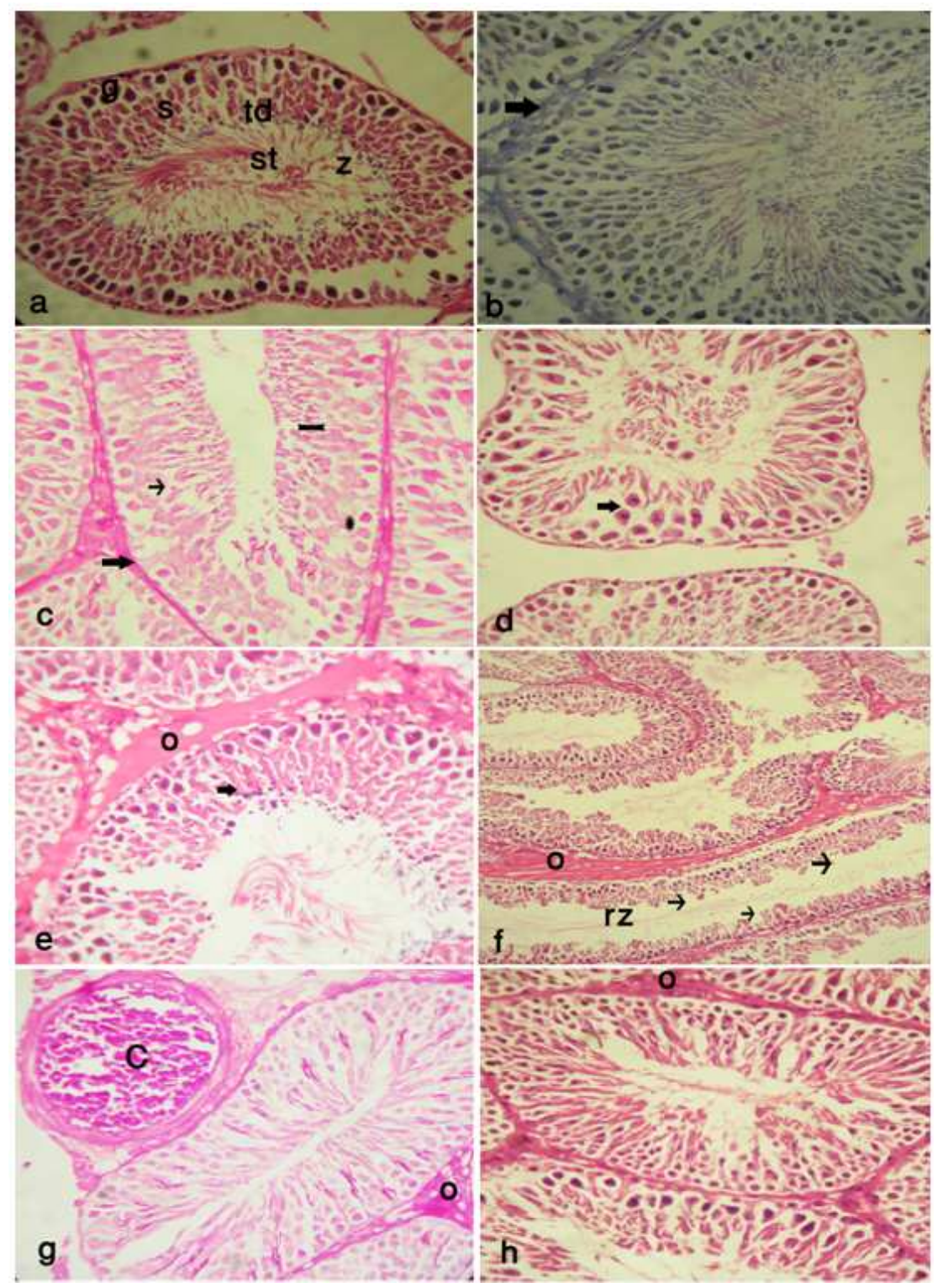

Fig. 3. Photomicrograph of testes of control, TiO2 and NAC administred rats. In (a), testes characterized by well organized seminiferous tubules (st), which consisted of spermatogonium (g), primary and secondary spermatocytes (s), spermatid(td) and spermatozoa (z); H\&E .X40. In (b), fine collagen fibres with blood vesseles represent the interstitial CT between the seminiferous tubules (arrow). Masson trichrome X40. In (c), the rat testes showed positive PAS reaction in the basement membrane (thick arrow), sertoli cells $\left(^{*}\right)$ and spermatozoa (-), while faint PAS reaction was detected in the spermatogenic cells (arrow) PAS X 40. In (d). The testes of the Tio2 administerd group showed appotosis of sertoli cells (arrow) H\&EX 40. In (e), numerous interstitial oedema spreaded between the seminiferous tubules (o) and appotosis of germinal layers were also detected (arrow), H\&E X40. In (f), some seminiferous tubules showed decrease in the thickness of the germinal layer (arrows) with rare sperms (rz) and interstitial oedema (o) H\&E X10. In (g), The testes in NAC and Tio2 administered rats showed partial improvement in the testicular cells while the congestion of the testicular blood vessels (C) and mild oedema (o) still persist PAS X40. In (h), the interstitial oedema was diminished in most of the seminiferous tubules while mild oedema still located in some parts of the interstital CT (o) and the general architecture of the testes was restored, H\&EX40. 
As seen in Fig. 2d, 17 $\beta$-HSD expression is down regulated in $\mathrm{TiO} 2$ administered rats and $\mathrm{NAC}$ normalized its expression. The overall effect of NAC alone as seen in Fig. 2 is stimulatory for spermatogenesis related gene expression.

\subsection{Histopathological Findings in Testes of Albino Rats after TiO2 and NAC Administration}

The testes of the control group were consisted of seminiferous tubules surrounded by interstitial connective tissue (CT). The seminiferous tubules lined by spermatogonium, primary and secondary spermatocytes, spermatid and spermatozoa. Pyramidal cells were located between the spermatogenic cells (Sertoli cells). Numerous interstitial cells (Leydig cells) were located in the interstital CT (Fig. 3a). The interstial CT mainly consisted of fine collagen fibers. Blood vessels were located between the interstitial $\mathrm{CT}$ in the testes of the NAC group (Fig. 3b). Positive PAS reaction was noticed in the basement membrane, sertoli cells and spermatozoa (Fig. 3c), while faint PAS reaction was detected in the spermatogenic cells. The testes of the $\mathrm{TiO} 2$ administerd group showed apoptosis of sertoli cells (Fig. 3d), numerous interstitial oedema spreaded between the seminiferous tubules and apoptosis of germinal layers were also detected (Fig. 3e), some seminiferous tubules showed decrese in the thickness of the germinal layer with rare sperms (Fig. 3f). The testes in NAC and $\mathrm{TiO} 2$ administered rats showed partial improvement in the testicular cells while the congestion of the testicular blood vessels and mild oedema still persist (Fig. 3g), the interstitial oedema was diminished in most of the seminiferous tubules while mild oedema still located in some parts of the interstital CT and the general architecture of the testes were restored (Fig. 3h).

\section{DISCUSSION}

In this study, we have reported the importance of NAC on testes function and its antiapoptotic and antiinflammatory effect and its role in protection of testes. As known, NAC and L-carnitine are highly concentrated in the epididymis and spermatozoa, it serves as an intramitochondrial adjuvent for the acyl group in the form of acyl CoA that acts as a substrate for fatty acids oxidation to produce energy for sperm respiration and motility (Kanter et al., 2010). Accumulation of $\mathrm{TiO} 2$ in testes down regulated genes responsible for cholesterol transport and steroidogenesis including ABP, P450scc, $17 \beta$-HSD, CYP-17 $\alpha$ and aromatase. Expression of ABP, CYP17 $\alpha$ and $17 \beta-H S D$ were significantly decreased in rats following exposure to $\mathrm{TiO} 2$ for 3 months. These genes play important roles in testosterone biosynthesis, for example, progesterone is converted to $17 \alpha$ hydroxyprogesterone and androstenedione by CYP17 $\alpha$. Then testosterone is sythesized from androstenedione by $17 \beta$-HSD. The decrease in gene expression of CYP17 $\alpha$ and $17 \beta-$ HSD indicates a possible contribution of these genes to the decrease in serum testosterone of male rats.

Apoptosis is a programmed cell death, it affects cell function and viability. BcL2 is known as apoptotic biomarker. Administration of $\mathrm{TiO} 2$ for 3 months upregulated BcL2 expression and NAC down regulate it confirming antiapoptotic activity of NAC as reported by ours and findings of (Aggarwal et al., 2010). Germ cell apoptosis play an important role in normal testicular function (Modi et al., 2003). It is required for normal spermatogenesis and is believed to ensure cellular homeostasis and maintain the balance between germ cells and Sertoli cells (Said et al., 2004). Also, apoptosis regulates spermatogenesis in health and disease status (Kerr, 1992). High rates of apoptosis was recorded in testicular biopsies from infertile men with variable degrees of testicular insufficiency (Juriscova et al., 1999). Sensitivity to factors modulated apoptosis was higher in the spermatogonia and spermatocytes, but Sertoli and Leydig cells were comparatively the most resistant (Kanter et al., 2010). Such changes was ameliorated and normalized by NAC administration.

In this study, $\mathrm{TiO} 2$ stimulated both oxidative stress that indicated by the decrease in reduced glutathione and inflammatory cytokines (IL-6 and TNF- $\alpha$ ). It has been shown that NAC ameliorated the decrease in GST and lipid peroxidation induced by diazion (Oksay et al., 2013). Moreover, the changes in cytokines expression induced by $\mathrm{TiO} 2$ are ameliorated by NAC administration. NAC acts as antioxidant that stimulate GSH synthesis (Dodd et al., 2008) and is confirmed in this study by up-regulation of testicular GST expression in $\mathrm{TiO} 2$ administered rats. So, NAC may restore the disturbance between pro-oxidant and antioxidant mechaisms during oxidative stress and that are coincided with our findings. In the epididymis, free antioxidants (NAC) are taken from circulating blood and actively transported through the epithelial cells into the epididymal plasma, using a specific carrier under regulation of androgens (Enomoto et al., 2002). Moreover, antioxidants especially L-carnitine and NAC act to protect the heart against ischemia/perfusion injuries that lead to myocyte death (Shug et al., 1991). 
The protective effect of NAC on testicular damage and dysfunction were explained in studies of Cay et al., 2006; Payabvash et al., 2007; Farombi et al., 2008; Aktas et al., 2010; Duarte et al., 2010. They showed that NAC had good effects on testicular dysfunction but they did not examine testicular gene alterations that examined in our study. Toxicity induction by tetracyclins increased testicular Malondialdehyde (MDA) levels and decreased superoxide dismutase, catalase, GSH and glutathione-STransferase (GST) levels. NAC significantly attenuated these effects as reported in our findings (Farombi et al., 2008). Moreover, high doses of $\mathrm{TiO} 2$ was shown to induce deleterious pathological changes, including rare sperm, sperm breakages, rarefaction of Sertoli cell and Sertoli cell apoptosis, necrosis of the seminiferous tubules, decreased germinative layer thickness, vaculation and irregular arrangement of sertoli cells of the seminiferous tubules (Gao et al., 2013).

Numerous studies have unequivocally shown that TiO2 exposure can migrate through different routes and accumulate in various organs (Chen et al., 2009; Shi et al., 2013; Jia et al., 2013), which, in turn cause oxidative stress, inflammation and apoptosis resulting in organ injury and failure. Dysfunction of the testes in turn affect reproduction and affects the function of the reproductive system (Jia et al., 2013). The cytochrome $\mathrm{P}-450$ aromatase enzyme, the ratelimiting enzyme in estradiol biosynthesis, it catalyzes the estradiol sythesis from testosterone. The present study demonstrated that aromatase mRNA levels decreased in $\mathrm{TiO} 2$ administered rats and NAC normalized aromatase expression in a way to control estradiol biosynthesis (Shi et al., 2007). It has been shown that NAC decrease diazinon induced oxidative stress in rat testes (Oksay et al., 2013) and improved semen quality and canine fertility (Michael et al. 2010).

ABP is a glycoprotein secreted from Sertoli cells in the seminiferous tubules. It binds to testosterone, dihydrotestosterone and 17-beta-estradiol. Higher levels of these hormones enable spermatogenesis in the seminiferous tubules and improve sperm maturation in the epididymis (Patrao et al., 2009). So, NAC probably acts to stimulate spermatogenesis through the increase in ABP expression. Moreover, aromatase, or estrogen synthase, is responsible for a key step in the biosynthesis of estrogens. Aromatase catalyzes many reactions involved in steroidogenesis and helps in aromatization of androgens into estrogens (Lu et al., 2010). In our results TiO2 inhibited ABP, 17 $\beta$ -
HSD, CYP17 $\alpha$ and aromatase expression while NAC administration has significant upregulation in steroidogenesis gene expression. Co-administration of NAC induced partial improvement in the testicular dysfunction, germinal layer apoptosis and diminished the interstitial oedema in most of the seminiferous tubules induced by $\mathrm{TiO} 2$.

\section{CONCLUSION}

The findings of this study confirmed that coadministration of NAC inhibited harmful effects of TiO2 that disrupted testicular function of male albino rats. NAC has antioxidant and antiapoptotic functions. Moreover, it improved steroidogenesis related gene expression which is ameliorated by $\mathrm{TiO} 2$ administration. NAC is a good health supplement for protection of male fertility from environmental toxic biohazards.

\section{REFERENCES}

Aggarwal, A., M.M. Misro, A. Maheshwari, N. Sehgal and D. Nandan, 2010. N acetylcysteine counteracts oxidative stress and prevents hCG-induced apoptosis in rat Leydig cells through down regulation of caspase- 8 and JNK. Mol. Reprod. Dev., 77: 900-909. PMID: 20824644

Aktas, B.K., S. Bulut, S. Bulut, M.M. Baykam and C. Ozden et al., 2010. The effects of $\mathrm{N}$-acetylcysteine on testicular damage in experimental testicular ischemia/reperfusion injury. Pediatr. Surg. Int., 26: 293-298. PMID: 19911182

Arend, W.P. and C. Gabay, 2004. Cytokines in the rheumatic diseases. Rheum. Dis. Clin. North Am., 30: 41-67. PMID: 15061568

Atkuri, K.R., J.J. Mantovani, L.A. Herzenberg and L.A. Atkuri, 2007. N-Acetylcysteine-asafe antidote for cysteine/glutathione deficiency. Curr. Opin. Pharmacol., 7: 355-359. PMID: 17602868

Carson, F., 1990. Histotechnology: A Self-instructional Text. 3rd Edn., ASCP Press, Chicago, ISBN-10: 0891895817, pp: 400.

Cay, A., A. Alver, M. Kucuk, O. Isşik and M.S. Eminagaoglu et al., 2006. The effects of Nacetylcysteine on antioxidant enzyme activities in experimental testicular torsion. J. Surg. Res., 131: 199-203. PMID: 16412470

Chen, J., X. Dong, J. Zhao and G. Tang, 2009. In-vivo acute toxicity of titanium dioxide nanoparticles to mice after intraperitioneal injection. J. Applied Toxicol., 29: 330-337. DOI: 10.1002/jat.1414 
Choi, H., E. Stathatos and D.D. Dionysiou, 2006. Sol-gel preparation of mesoporous photocatalytic $\mathrm{TiO} 2$ films and $\mathrm{TiO} 2 / \mathrm{A} 12 \mathrm{O} 3$ composite membranes for environmental applications. Applied Catal. B Environ., 63: 60-67. DOI: 10.1016/j.apcatb.2005.09.012

Dodd, S., O. Dean, D.L. Copolov, G.S. Malhi and M. Berk, 2008. N-acetylcysteine for antioxidant therapy: Pharmacology and clinical utility. Expert Opin. Biol. Ther., 8: 1955-1962. PMID: 18990082

Duarte, F., R. Blaya, P.E. Teloken, D. Becker and M. Fernandes et al., 2010. The effects of N-acetylcysteine on spermatogenesis and degree of testicular germ cell apoptosis in an experimental model of varicocele in rats. Int. Urol. Nephrol., 42: 603-608. PMID: 20012359

Enomoto, A., M.F. Wempe and H. Tsuchida, 2002. Molecular identification of a novel carnitine transporter specific to human testes: Insights into the mechanism of carnitine recognition. J. Biol. Chem., 277: 36262-36271. PMID: 12089149

Farombi, E.O., M.C. Ugwuezunmba, T.T. Ezenwadu, M.O. Oyeyemi and M. Ekor, 2008. Tetracyclineinduced reproductive toxicity in male rats: Effects of vitamin $\mathrm{C}$ and $\mathrm{N}$-acetylcysteine. Exp. Toxicol. Pathol., 60: 77-85. PMID: 18406588

Feghali, C.A. and T.M. Wright, 1997. Cytokines in acute and chronic inflammation. Front. Biosci., 2: 12-26. PMID: 9159205

Fisher, J. and T. Egerton, 2001. Titanium Compounds, Inorganic. In: Kirk-Othmer Encyclopedia of Chemical Technology, Kroschwitz, J.I. and A. Seidel (Eds.), Wiley-Interscience, Hoboken, NJ.

Gao, G., Y. Ze, X. Zhao, X. Sang and L. Zheng et al., 2013. Titanium dioxide nanoparticles induced testicular damage, spermatogenesis suppression andgene expression alterations in male mice. $\mathrm{J}$. Hazard Mater., 258-259: 133-143. PMID: 23721730

Hoet, P.H., I. Brske-Hohlfeld and O.V. Salata, 2004. Nanoparticles-known and unknown health risks. J. Nanobiotechnol., 2: 12-12. DOI: 10.1186/14773155-2-12

Jia, F., Z. Sun, X. Yan, B. Zhou and J. Wang, 2013. Effect of pubertal nano-TiO2 exposure on testosterone synthesis and spermatogenesis in mice. Arch. Toxicol. PMID: 24241477

Juriscova, A., S. Lopes and J. Merrano, 1999. DNA damage in round spermatids of mice with targeted disruption of the Pp1c 75 gene and in testicular biopsies of patients with non-obstructive azoospermia. Mol. Hum. Reprod., 5: 323-330. PMID: 10321803
Kaida, T., K. Kobayashi, M. Adachi and F. Suzuki, 2004. Optical characteristics of titanium oxide interference film and the film laminated with oxides and their applications for cosmetics. J. Cosmet. Sci., 55: 219-220. PMID: 15190897

Kanter, M., Y. Topcu-Tarladacalisir and S. Parlar, 2010. Antiapoptotic effect of L-carnitine on testicular irradiation in rats. J. Mol. Hist., 41: 121-128. PMID: 20446105

Kerr, J.B., 1992. Spontaneous degeneration of germ cells in rat testes: Assessment of cell types and frequency during the spermatogenic cycle. J. Reprod. Fertil., 95: 825-830. PMID: 1404097

Kiernan, J.A., 1999. Histological and Histochemical Methods: Theory and Practice. 3rd Edn., Butterworth Heinemann, Boston, ISBN-10: 0750631066, pp: 502.

Li, N., Y.M. Duan, M.M. Hong, L. Zheng and M. Fei et al., 2010. Spleen injury and apoptotic pathway in mice caused by titanium dioxide nanoparticules. Toxicol. Lett., 195: 161-168. PMID: 20381595

Lu, X., T. Yu, M. Ma, C. Jin, Q. Liu and S. Wu et al., 2010. Effect on the testes development and StAR, CYP19a1 and CYP11a1 expression of prepubertal male rats after sub-acute exposure to DEHP. Wei. Sheng, 39: 263-267. PMID: 20568448

Medina, C., M.J. Santos-Martinez and A. Radomski, 2007. Nanoparticles: Pharmacological and toxicological significance. Br. J. Pharmacol., 150: 552-558. PMID: 17245366

Michael, A.J., C. Alexopoulos, E.A. Pontiki, D.J. Hadjipavlou-Litina and P. Saratsis et al., 2010. Effect of N-acetyl-L-cysteine supplementation in semen extenders on semen quality and reactive oxygen species of chilled canine spermatozoa. Reprod. Domest. Anim., 45: 201-217. PMID: 19508647

Modi, D.N., S. Sane and D. Bhartiya, 2003. Accelerated germ cell apoptosis in sex chromosome aneuploid fetal human gonads. Mol. Hum. Reprod., 9: 219225. PMID: 12651904

Moschou, M., E.K. Kosmidi, M. Kaloyianni, A. Geronikaki and N. Dabarakis et al., 2008. In vitro assessment of the neurotoxic and neuroprotective effects of N-Acetyl-L-Cysteine (NAC) on the rat sciatic nerve fibers. Toxicol. Vitro, 22: 267-274. PMID: 17959349

Oberdorster, G., 2006. Toxicology of air born environment and occupational particles. 
Oksay, T., M. Nazırogolu, O. Erguun, S. Dogan and O. Ozatik et al., 2013. N-acetyl cysteine attenuates diazinon exposure-induced oxidative stress in rat testes. Andrologia, 45: 171-177. PMID: 22742659

Patrao, M.T., E.J. Silva and M.C. Avellar, 2009. Androgens and the male reproductive tract: An overview of classical roles and current perspectives. Arq. Bras. Endocrinol. Metabol., 53: 934-945. PMID: 20126845

Payabvash, S., A.H. Salmasi, S. Kiumehr, S.M. Tavangar and B. Nourbakhsh et al., 2007. Salutary effects of $\mathrm{N}$-acetylcysteine on apoptotic damage in a rat model of testicular torsion. Urol. Int., 79: 248254. DOI: $10.1159 / 000107958$

Sadowska, A.M., B. Manuel-y-Keenoy and W.A. De Backer, 2007. Antioxidant and anti-inflammatory efficacy of NAC in the treatment of COPD: Discordant in vitro and in vivo dose-effects: A review. Pulmonary Pharmacol. Therapeutics, 20: 922. PMID: 16458553

Said, T.M., U. Paasch and H.J. Glander, 2004. Role of caspases in male infertility. Hum. Reprod. Update, 10: 39-51. PMID: 15005463

Sang, X.Z., L. Zheng, Q.Q. Sun, T. Zhang and N. Li et al., 2012. The chronic spleen injury of mice following exposure to titanium dioxide nanoparticules. J. Biomed. Mater. Res., Part A, 100: 894-902. PMID: 22275130

Sen, C.K. and L. Packer, 2000. Thiol homeostasis and supplements in physical exercise. Am. J. Clin. Nutr., 72: 653S-69S. PMID: 10919972

Shi, H., R. Magaye, V. Castranova and J. Zhao, 2013. Titanium dioxide nanoparticles: A review of current toxicological data. Part Fibre. Toxicol., 10: 15-15. DOI: $10.1186 / 1743-8977-10-15$

Shi, Z., H. Zhang, Y. Liu, M. Xu and J. Dai, 2007. Alterations in gene expression and testosterone synthesis in the testes of male rats exposed to perfluorododecanoic acid. Toxicol. Sci., 98: 206215. PMID: 17400581
Shug, A., A. Paulson, R. Subramanian and V. Regitz, 1991. Protective effects of propionyl-L-carnitine during ischaemia and reperfusion. Cardiovasc. Drugs Ther., 5: 77-83. PMID: 2031875

Stanislawski, L., M. Lefeuvre, K. Bourd, M.E Soheili and M. Goldberg et al., 2003. TEGDMA-induced toxicity in human fibroblasts is associated with early and drastic glutathione depletion with subsequent production of oxygen reactive species. J. Biomed. Mat. Res., 66A: 476-482. PMID: 12918029

Stanislawski, L., M.E. Soheili, A. Perianin and M. Goldberg, 2000. Dental restorative biomaterials induce glutathione depletion in cultured human gingival fibroblast: Protective effect of $\mathrm{N}$-acetyl cysteine. J. Biomed. Mat. Res., 51: 469-474. PMID: 10880090

Turner, T.T. and J.J. Lysiak, 2008. Oxidative stress: a common factor in testicular dysfunction. J. Androl., 29: 488-498. PMID: 18567643

Van de Poll, M.C.G., C.H.C. Dejong and P.B. Soeters, 2006. Adequate range for sulfur-containing amino acids and biomarkers for their excess: Lessons from enteral and parenteral nutrition. J. Nut., 136: 1694S1700S. PMID: 16702341

Wang, J., G. Zhou, C. Chen, H. Yu and T. Wang et al., 2007. Acute toxicity and biodistribution of different sized titanium dioxide particles in mice after oral administration. Toxicol. Let., 168: 176-185. PMID: 17197136

Wilson, I. and M. Gamble, 2008. The Hematoxylins and Eosins. In: Theory and Practice of Histological Techniques, Bancroft, J.D. and M. Gamble (Eds.), Elsevier Health Sciences, London, UK., ISBN-10: 0443102791, pp: 125-138.

Zafarullah, M., W.Q. Li, J. Sylvester and M. Ahmad, 2003. Molecular mechanisms of $\mathrm{N}$-acetylcysteine actions. Cellular Mol. Life Sci., 60: 6-20. PMID: 12613655 